\title{
REMARKS ON THE MARINER 2 LIMB-DARKENING MEASUREMENTS
}

\author{
par L. D. KaPLAN
}

(Jet Propulsion Laboratory, Pasadena, Calif, U. S. A.)

Rfisumf. - On montre que les observations radiométriques de l'assombrissement centre-bord de Vénus faites à partir de Mariner II ne peuvent étre interprétées uniquement en fonction de la structure nuageuse ou de la distribution verticale de la température. Il est nécessaire de mesurer aussi le spectre d'absorption de façon précise pour comprendre la nature de l'atmosphère de Vénus au voisinage des nuages.

Adstract. - It is shown that the limb-darkening observed in the radiometric measurements of Venus cannot be interpreted unambiguously in terms of cloud structure or vertical temperature distribution. In order to understand the nature of the Venus atmosphere in the vicinity of the clouds, these data have to be supplemented with accurate measurements in the absorption spectrum.

Ревюме. - Показано, что радиометрические наблюдения потемнения от центра к краю Венеры, проведенные с борта Маринер II, не могут быть интерпретированы лишь в зависимости от облаковой структуры или от вертикального распределения температуры. Необходимо также точно измерять спектр поглощения, чтобы понять природу атмосферы Венеры вблизи облаков.

In my article with Chase and NeUgebauer 1963) on the results of the Mariner 2 Infrared Radiometer Experiment which was presented at the Liege Astrophysical Colloquium last year, we pointed out that " Although the data indicated a crude power law dependence, they can be fitted to an exponential law equally well and no detailed conclusions about cloud structure can be made". As an extension of Dr. SAGAN's discussion of the ambiguity of the results in the preceding paper of the present session, it is appropriate that I elaborate on our statement and extend his discussion to include the case of stratified clouds.

The equality of the brightness temperature in the $\mathrm{CO}_{2}$ channel at $10.4 \mu$ and the transparent channel at 8.4 $\mu$ indicated that all of the radiation received came from the clouds. If the clouds are distributed uniformly by mass in the atmosphere, the radiation reaching the radiometer, in the entrance cone for which $\overline{\mathrm{B}}_{v}$ is the black-body radiation, is given by

$$
\text { (1) } \uparrow=-\int_{1}^{0} \overline{\mathrm{B}}_{\nu} d \mathrm{e}^{-k \mathrm{P} / \mu}=\int_{k \mathrm{P}_{\mathbf{T}} / \mu}^{\infty} \overline{\mathrm{B}}_{\nu} \mathrm{e}^{-x} d x,
$$

where $k$ is the absorption coefficient per unit weight, $P_{T}$ the pressure at the cloud top, and $\mu$ the cosine of the viewing direction with the vertical. For a small range of temperature $T$, the black body radiation in the frequency considered can be represented by

$$
\overline{\mathrm{B}}_{v}=a \mathrm{~T}^{n} \text {, }
$$

where $a$ and $n$ are empirical constants. We will further assume that the variation of temperature with height has the constant value of $-\gamma$, so that

$$
\mathrm{T} / \mathrm{T}_{0}=\left(\mathrm{P} / \mathrm{P}_{0}\right)^{\mathrm{R} / m \theta}
$$

where $T_{0}$ is the temperature at some pressure $P_{0}$ within the cloud, say at the cloud top.

Substitution of (2) and (3) in (1) yields

$$
\uparrow=a_{1}(\mu / k)^{a_{\mathbf{s}}} \int_{k \mathrm{P}_{\mathbf{T}} / \mu}^{\infty} x^{a_{\mathbf{1}}} \mathrm{e}^{-x} d x,
$$

where

$$
a_{1}=a \mathrm{~T}_{0}^{n} \mathrm{P}_{0}^{-a_{1}},
$$

and

$$
a_{2}=n \mathrm{R} \gamma / m g
$$

If the clouds extend to great heights in the atmosphere, there will be a height above which the cloud absorption and emission is negligible and where the variation of temperature with height is unimportant. Under these conditions, the lower limit of the integral in (4) can be taken as zero, and (4) becomes

$$
\uparrow=a_{1}(\mu / k)^{a_{2}} \Gamma\left(a_{2}+1\right),
$$

from which

$$
\text { (8) } \begin{aligned}
\log (1 / u)=a_{2}^{-1} \log \left[a_{1} \Gamma\right. & \left.\left(a_{2}+1\right)\right] \\
& -\log k-\frac{1}{a_{2}} \log \uparrow .
\end{aligned}
$$


Figure 14 of our original paper (CHAse et al., 1963) shows that, apart from a temperature anomaly in the southern hemisphere, the data behave in accordance with (8) as the run of energy received vs. air mass fits a straight line on the logarithmic scale. From the slope of the line, $\gamma$ has a value approximately one-third of the adiabatic lapse-rate if the mean molecular weight of Venus air is close to that for Earth.

Unfortunately, the fit of the data to a power law does not prove the correctness of the cloud model assumed, since the same result can be obtained by varying both the cloud density and vertical temperature gradient with height. In fact, the data are even consistent with stratified cloud models. To demonstrate this, we will consider an extreme model in which a thin, semi-transparent cloud layer is separated by a transparent air layer from an underlying dense cloud, which radiates as a black body corresponding to its upper temperature.

Let this black body radiation be $\mathrm{BL}_{\mathrm{L}}$ and that corresponding to the temperature of the thin upper cloud layer be $B_{0}$. Then the radiation. received by the radiometer is

$$
\uparrow=B_{\mathrm{L}} \mathrm{e}^{-\tau / \mu}+\mathrm{B}_{\mathrm{U}}\left(1-\mathrm{e}^{-\tau / \mu}\right)
$$

where $\tau$ is the optical thickness of the upper cloud in the vertical. We will now assume that the temperature of the upper cloud is low enough compared to that of the lower cloud that $\mathbf{B}_{\boldsymbol{\sigma}} \ll \uparrow$. Then (9) becomes

$$
\tau / \mu=B_{\mathrm{L}}-\log _{e} \uparrow .
$$

This would correspond to a straight line on our Figure 14 if the abscissa were expanded from a logarithmic scale to a linear scale. Visual inspection of the figure will show that the data fit a straight line on such a revised graph equally as well as they do in the original figure. To discriminate between these two extreme models, the data would have to be taken at larger airmasses than is practically possible.

It is my opinion that the most useful data for obtaining the cloud stratification, would be very accurate equivalent widths of the individual rotation lines of the vibrational bands that appear in the near infrared reflected solar radiation. These data can be obtained by careful measurements from earth-based telescopes.

Manuscrit reçu le 12 novembre 1964.

\section{REFERENCES}

Chase S., Kaplan L. D. and Neggebauter G., 1963, The Mariner 2 Infrared Radiometer Experiment, J. Geophys. Res., 68, 6157.

[1] Danthlson R. E., Gaustad J. E., Sohwarzs-
OHIID M., Wraver H. F. and Woolf N. J., Astron. J., 69, 344. 1964,

[2] Kaplan L. D., MüNor G. and Spinrad H., 1964, Ap. J., 189, 1. 